\title{
GENERALIZED MONOTONE ITERATIVE METHOD FOR INTEGRO DIFFERENTIAL EQUATIONS WITH PERIODIC BOUNDARY CONDITIONS
}

\author{
IANNA H. WeSt AND A. S. VATSALA
}

\begin{abstract}
In this paper, we will develop a generalized monotone iterative method for first order nonlinear integro differential equations with periodic boundary conditions when the forcing function is the sum of an increasing and decreasing function. We obtain natural monotone sequences or alternating monotone sequences depending on the coupled upper and lower solution used and depending on the iterative scheme used to develop the sequence. These sequences converge to coupled extremal solutions of the integro differential equation.
\end{abstract}

Mathematics subject classification (2000): 45J05, 34K10.

Key words and phrases: monotone method, periodic boundary conditions.

\section{REFERENCES}

[1] S. R. Bernfeld, V. LAKShmikAntham, An Introduction to Nonlinear Boundary Value Problems, Academic Press, 1973.

[2] T. G. BhaskaR, F. A. MCRAE, Monotone Iterative Techniques for nonlinear Problems Involving the Difference of two Monotone Functions, Applied Mathematics and Computation, 133, (2002), 187-192.

[3] G. S. LadDE, V. LAKShmiKantham AND A. S. Vatsala, Monotone Iterative Techniques for Nonlinear Differential Equations, Pitman Publishing Inc, 1985.

[4] V. LaKSHMikantham, A. S. VATSALA, Generalized Quasilinearization and Nonlinear Problems, Kluwer Academic Publishers, 1998.

[5] V. Lakshmikantham, M. Rama Mohana RaO, Theory of Integro-differential Equations, Gordon and Breach Science Publishers, 1995.

[6] M. SoKol, A. S. VATSALA, A Unified Exhaustive Study of Monotone Iterative Method for Initial Value Problems, Nonlinear Studies, 8, (4) (2001), 429-438.

[7] A. S. VAtSAla, I. H. ReED, Generalized Monotone Iterative Method For Initial Value Problems, to appear in Applied Mathematics Letters.

[8] I. H. West, A. S. Vatsala, M. Sokol, Generalized Monotone Iterative Method for Second Order Boundary Value Problems. 